\title{
Tautomerism in azo dyes: Border cases of azo and hydrazo tautomers as possible NMR reference compounds
}

\author{
V. Deneva ${ }^{\mathrm{a}}$, A. Lyčka ${ }^{\mathrm{b}, * *}$, S. Hristova ${ }^{\mathrm{a}}$, A. Crochet $^{\mathrm{c}}$, K.M. Fromm ${ }^{\mathrm{c}}$, L. Antonov ${ }^{\mathrm{a}, *}$ \\ ${ }^{a}$ Institute of Organic Chemistry with Centre of Phytochemistry, Bulgarian Academy of Sciences, Acad. G. Bonchev str., bl. 9, 1113, Sofia, Bulgaria \\ ${ }^{\mathrm{b}}$ Faculty of Science, University of Hradec Králové, Rokitanského 62, CZ-500 03, Hradec Králové III, Czech Republic \\ ${ }^{\mathrm{c}}$ University of Fribourg, Department of Chemistry, Chemin du Musée 9, CH-1700, Fribourg, Switzerland
}

\section{A R T I C L E I N F O}

\section{Keywords:}

Tautomerism

Azo dyes

NMR

UV-Vis

Quantum chemistry

\section{Introduction}

According to the classification of dyes, $60-70 \%$ of them are azo compounds, which except conventional use, show applicability in science and technology as optical materials, in molecular data processing, as ion sensors and in biological applications [1]. At the same time, a substantial part of the azo dyes are tautomeric or potentially tautomeric [2-5]. Taking into account that the color and the stability of dyes are strongly influenced by their tautomerism, it is not surprising that this phenomenon has been intensively studied theoretically and experimentally during the past years [6].

It is well known that the position of the tautomeric equilibrium in solution depends on structural factors as well as on external stimuli like temperature, solvents, light, $\mathrm{pH}$, etc. [1,7,8]. Although a variety of techniques has been used to study tautomeric systems [9], UV-Vis spectroscopy and NMR remain the major experimental tools for their investigation in solution [10]. However, both techniques experience difficulties in distinguishing the spectral responses of the pure tautomeric forms when they co-exist in solution.

Taking into account that the proton transfer is slower than the electron excitation, the UV-Vis spectroscopy records tautomers as individual species with different, but unknown, spectral characteristics.
Under certain conditions, the problem with unknown pure spectra of the tautomers can be overcome by using advanced chemometrics $[11,12]$. The proton exchange between nitrogen and oxygen atoms in azodyes is fast at the NMR time scale. As a result an averaged signal is typically measured $[10,13]$ and reference compounds are needed to evaluate the proportion of the tautomers. The quantitative results very strongly depend on the selected references representing the pure azo and hydrazo tautomers. Consequently, there is a need such reference compounds to be identified and used in the NMR investigations of tautomeric azodyes.

Therefore, the aim of the current study is to reveal the tautomeric state of compounds 1-6 (Scheme 1) in solution and in the solid state by using NMR, UV-Vis spectroscopy, crystallography and theoretical investigations. As seen from Scheme 1, these compounds can potentially exist as enol-like azo (a) or keto-like hydrazone (b) forms, and if the tautomeric equilibrium is shifted to one of the pure tautomers, they can be used as reference compounds for NMR investigations of tautomeric azo dyes. The effect of insertion of a nitro group is considered in the light of possible stabilization of the keto-like tautomer [7] through a pure electron acceptor effect (3 and 6) and through mixed electron acceptor action and possible hydrogen bonding ( 2 and 5 ). In our best knowledge no such detailed investigations of the tautomerism of 1-6

\footnotetext{
* Corresponding author.

** Corresponding author.

E-mail addresses: antonin.lycka@vuos.com (A. Lyčka), lantonov@orgchm.bas.bg (L. Antonov).
} 
<smiles>[R2]c1ccc(N=Nc2c(C)nn(-c3ccccc3)c2N)c([R7])c1</smiles><smiles>[R]c1ccc(N/N=C2\C(=O)N(c3ccccc3)N=C2C)c([R])c1</smiles>

$1 \mathrm{R}_{1}=\mathrm{R}_{2}=\mathrm{H}$

$2 \mathrm{R}_{1}=\mathrm{NO}_{2} \quad \mathrm{R}_{2}=\mathrm{H}$

$3 \mathrm{R}_{1}=\mathrm{H} \mathrm{R}_{2}=\mathrm{NO}_{2}$

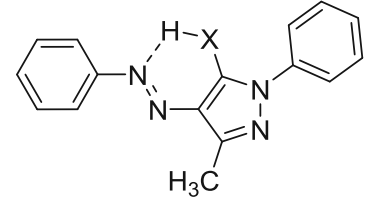

a
$4 \mathrm{R}_{1}=\mathrm{R}_{2}=\mathrm{H}$

$5 \mathrm{R}_{1}=\mathrm{NO}_{2} \quad \mathrm{R}_{2}=\mathrm{H}$

$6 \mathrm{R}_{1}=\mathrm{H} \mathrm{R}_{2}=\mathrm{NO}_{2}$

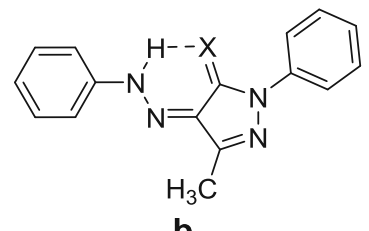

b
Scheme 1. Investigated compounds 1-6 (top) and sketch of their tautomeric forms (bottom, azo, enol-like $\mathbf{a}$ and hydrazo, keto-like $\mathbf{b}, \mathrm{X}=\mathrm{O}$ or $\mathrm{NH}$ ).

was performed before, especially by using combined experimental and theoretical approach, which definitely confirms the tautomeric state of each of the studied compounds.

\section{Experimental part}

\subsection{Synthesis}

Compounds 1-6 were prepared using appropriate diazononium salts coupling reactions with 5-amino-3-methyl-1-phenylpyrazole and 3methyl-1-phenylpyrazol-5-one, respectively, in acetic acid. Separated raw products obtained in high yields were crystallized from ethanol. Purity and homogeneity of the samples were checked using ${ }^{1} \mathrm{H}$ NMR. Elemental analysis data (Calc./Found, in \%): 1 (C 69.29/69.5, H 5.45/ 5.4, N 25.25/25.2), 2 (C 59.62/59.8, H 4.38/4.4, N 26.07/25.9), 3 (C 59.62/59.8, H 4.38/4.3, N 26.07/26.2), 4 (C 69.05/69.1, H 5.07/5.0, N 20.13/20.2), 5 (C 59.44/59.6, H 4.05/4.2, N 21.66/21.4), 6 (C 59.44) 59.5, H 4.05/4.1, N 21.66/21.7).

\section{2. $N M R$}

The ${ }^{1} \mathrm{H},{ }^{13} \mathrm{C}$ and ${ }^{15} \mathrm{~N}$ NMR spectra were recorded on a Bruker Avance III HD 400 spectrometer operating at $400.13 \mathrm{MHz}$ for ${ }^{1} \mathrm{H}, 100.62 \mathrm{MHz}$ for ${ }^{13} \mathrm{C}$ and at $40.56 \mathrm{MHz}$ for ${ }^{15} \mathrm{~N}$ and using liquid nitrogen-cooled 5mm Prodigy cryo probe (Bruker) at $300 \mathrm{~K}$. The samples 1-6 were dissolved in deuteriochlorofom. The ${ }^{1} \mathrm{H}$ and ${ }^{13} \mathrm{C}$ chemical shifts were referenced to internal TMS $(\delta=0.00)$. The ${ }^{15} \mathrm{~N}$ chemical shifts were referred to the signal of external nitromethane placed in a co-axial capillary $(\delta=0.0)$. All 2D experiments (gradient-selected (gs)-COSY, gs-HMQC, gs-HSQC, and gs-HMBC) and $1 \mathrm{D}{ }^{1} \mathrm{H}-{ }^{15} \mathrm{~N}$ gs-HSQC were performed using manufacturer's software (TOPSPIN 3.5) [14-16].

\subsection{UV-Vis measurements}

Spectral measurements were performed on a Jasco V-570 UV-VisNIR spectrophotometer, equipped with a thermostatic cell holder (using Huber MPC-K6 thermostat with precision $1{ }^{\circ} \mathrm{C}$ ) in spectral grade solvents at $20^{\circ} \mathrm{C}$.

\subsection{X-ray measurements}

Suitable crystals were selected and mounted on a loop in oil on a STOE IPDS2T (compounds 1 and 3) or STOE IPDS2 (compounds 4 and 5) diffractometer. Crystals were kept at $T=200(2) \mathrm{K}$ during data collection, except for $4(T=250(2) \mathrm{K})$. Using Olex2 [17], the structures were solved with the ShelXT structure solution program [18], using the
Intrinsic Phasing solution method. The models were refined with version $2017 / 1$ of ShelXL [19] using Least Squares minimization. All structures have been labelled with the same order (Scheme S1), all crystallographic data are available on Table S7, selected distances and hydrogen bond tables are available in the SI (Tables S8-S12).

The single crystal data has been deposited at the Cambridge Crystallographic Data Centre and allocated the deposition number CCDC-1844620 (1), 1844622 (3), 1844623 (4) 1844621 (5).

\subsection{Quantum chemical calculations}

Quantum-chemical calculations were performed by using the Gaussian 09 program suite [20]. If not explicitly described, the M06-2X functional [21,22] was used with TZVP basis set [23]. This fitted hybrid meta-GGA functional with $54 \%$ HF exchange is specially developed to describe main-group thermochemistry and the non-covalent interactions, showing very good results in prediction of the position of the tautomeric equilibrium in azo naphthols possessing intramolecular hydrogen bonds [24,25] and in description of the proton transfer reactions in naphthols [26]. All structures were optimized without restrictions, using tight optimization criteria and ultrafine grid in the computation of two-electron integrals and their derivatives, and the true minima were verified by performing frequency calculations in the corresponding environment. Solvent effects are described by using the Polarizable Continuum Model (the integral equation formalism variant, IEFPCM, as implemented in Gaussian 09) [27]. The absorption spectra of the compounds were predicted using the TD-DFT formalism. TD-DFT calculations were carried out at the same functional and basis set, which is in accordance with conclusions about the effect of the basis set size and the reliability of the spectral predictions [28-32].

The NMR chemical shieldings of selected tautomeric forms of the studied compounds were calculated using the GIAO approximation [33] at the B3LYP/6-311 + G(2d,p) level of theory. This level of theory was recommended in the pioneering work by Cheeseman et al. [34] focused on the comparison of different models for calculating nuclear magnetic resonance shielding tensors and shows very good results in predicting the NMR spectra of azo-hydrazone tautomerism [35]. For comparison purposes the values obtained by using M06-2X/TZVP are presented as well. The calculated absolute shieldings were transformed to chemical shifts using the reference compound tetramethylsilane, $\mathrm{Si}\left(\mathrm{CH}_{3}\right)_{4}$, for carbon and hydrogen atoms, and nitromethane, $\mathrm{CH}_{3} \mathrm{NO}_{2}$, for nitrogen atoms: $\delta=\delta_{\text {calc }}($ ref $)-\delta_{\text {calc }}$. Both $\delta_{\text {calc }}($ ref $)$ and $\delta_{\text {calc }}$ were evaluated at the same computational level.

\section{Results and discussion}

\subsection{In solution}

As seen from Scheme 1 the investigated compounds differ by the tautomeric proton donor group - NH in 1-3 and $\mathrm{OH}$ in 4-6. The UV-Vis spectra of the backbone structures $\mathbf{1}$ and $\mathbf{4}$ are compared in Fig. 1. The spectral data for the remaining compounds are compared in Fig. S1 (2 and 5) and S2 (3 and 6), Supplementary information, following the same $\mathrm{NO}_{2}$ substitution pattern. The spectra of 1 in different solvents (Fig. 1a) show a well-defined maximum around $375 \mathrm{~nm}$, while a band at $390 \mathrm{~nm}$ is observed in the case of 4 (Fig. 1b). Taking into account that the used solvents differ substantially by proton acceptor/donor action and polarity, the lack of spectral changes (as position of the band and as shape) can only mean that there is no tautomeric equilibrium in all studied compounds. This assumption is clearly confirmed by the theoretical results collected in Table 1 . As seen the relative stability of the tautomers suggest existence of the a-form in 1-3 and of the $\mathbf{b}$-tautomer in 4-6. The energy gap slightly depends on the solvent and, which is more important, is large enough to exclude appearance of the counter tautomer in solution even if large variations in the solvent dielectric constant are available. 


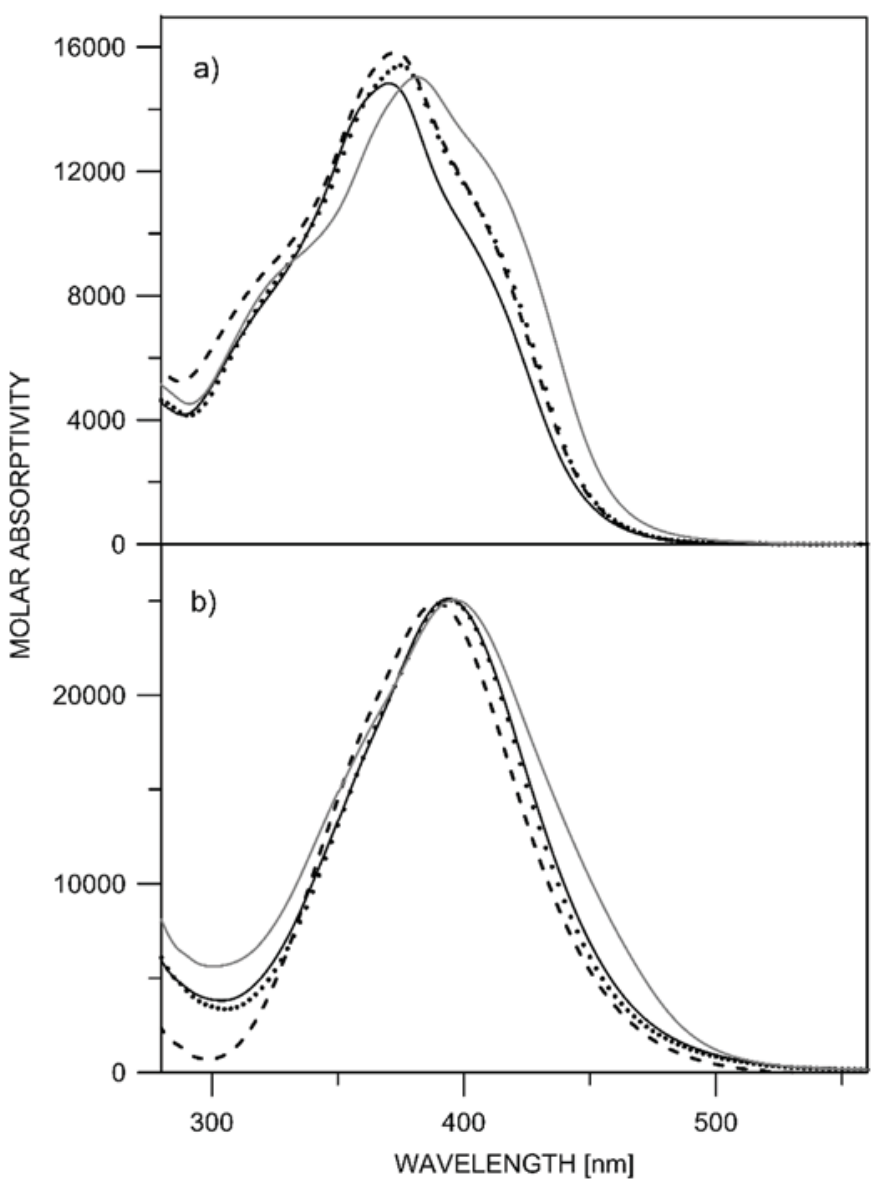

Fig. 1. Absorption spectra of in acetonitrile $(-)$, benzene $(\cdots)$, chloroform $(-)$ and DMSO (-) of 1 (a) and 4 (b).

Table 1

Predicted values (M062X/TZVP) for the relative stability and spectral characteristics of $\mathbf{a}$ and $\mathbf{b}$ forms of 1-6 in acetonitrile and chloroform.

\begin{tabular}{|c|c|c|c|c|c|c|}
\hline \multirow[t]{2}{*}{ compound } & \multirow[t]{2}{*}{ Solvent } & \multirow[t]{2}{*}{$\mathrm{E}_{\mathrm{a}}-\mathrm{E}_{\mathrm{b}}$ ** } & \multicolumn{2}{|l|}{ a-form } & \multicolumn{2}{|l|}{ b-form } \\
\hline & & & $\lambda_{\max }[\mathrm{nm}]$ & $f$ & $\lambda_{\max }[\mathrm{nm}]$ & $f$ \\
\hline \multirow[t]{2}{*}{1} & acetonitrile & 6.01 & 338 & 0.88 & 363 & 0.54 \\
\hline & chloroform & 5.55 & 340 & 0.91 & 365 & 0.55 \\
\hline \multirow[t]{2}{*}{2} & acetonitrile & 4.91 & 368 & 0.63 & 387 & 0.37 \\
\hline & chloroform & 4.95 & 370 & 0.66 & 387 & 0.38 \\
\hline \multirow[t]{2}{*}{3} & acetonitrile & 5.40 & 375 & 1.08 & 380 & 0.63 \\
\hline & chloroform & 5.06 & 374 & 1.10 & 380 & 0.62 \\
\hline \multirow[t]{2}{*}{4} & acetonitrile & -7.59 & 335 & 0.95 & 354 & 0.58 \\
\hline & chloroform & -7.39 & 337 & 0.97 & 356 & 0.53 \\
\hline \multirow[t]{2}{*}{5} & acetonitrile & -8.73 & 356 & 0.77 & 372 & 0.30 \\
\hline & chloroform & -8.19 & 359 & 0.82 & 375 & 0.20 \\
\hline \multirow[t]{2}{*}{6} & acetonitrile & -8.16 & 360 & 1.16 & 365 & 0.42 \\
\hline & chloroform & -7.82 & 362 & 1.18 & 368 & 0.30 \\
\hline
\end{tabular}

* $f$ - oscillator strength; ** relative stability (in $\mathrm{kcal} / \mathrm{mol}$ ), positive value means more stable a-form and vice versa.

Although the use of M06-2X functional leads to systematically blue shifted positions of the absorption bands [32], a comparison between the values in Table 1 and observed spectral maxima in Fig. 1 allows supporting the assumption for single tautomers in $\mathbf{1}$ and $\mathbf{4}$. As seen from Table 1 the maxima of the corresponding tautomers of $\mathbf{1}$ are slightly red shifted compared to $\mathbf{4}$. This means that if $\mathbf{1}$ and $\mathbf{4}$ are presented as the same tautomeric form (either $\mathbf{a}$ or $\mathbf{b}$ ), the same absorption maxima have to be observed in Fig. 1, which is not the case.

The relative stability of the tautomers, shown in Table 1, indicates that the structural modifications in 2-3 and 5-6 are not sufficient to cause dramatic change of their tautomerism. The pure electron acceptor effect of the nitro group in $\mathbf{2}$ shifts the position of the tautomeric state towards the keto-like tautomer by $\sim 1 \mathrm{kcal} / \mathrm{mol}$, but the energy gap remains large enough to prevent appearance of the $\mathbf{b}$-form in solution. The substitution effect in $\mathbf{3}$ is moderate, comparing to $\mathbf{2}$, probably because the electron acceptor action is reduced by the fact that both tautomers can participate in hydrogen boding with the nitro group oxygen atom (see Fig. 2, where the theoretically optimized structures are shown). The same tendencies towards stabilization of the hydrazone b-form are observed in $\mathbf{4}$ and $\mathbf{5}$.

The experimentally measured NMR data are collected in Tables 2 and 3, with the corresponding numbering given in Scheme 2. According to the NMR data, compounds 4-6 exist in b forms (Table 3). Compound 4 was proposed by Bekarek et al. [36] as a suitable model of a hydrazone compound. Electron accepting substituents in original anilines, used for the coupling reaction, typically stabilize the hydrazone forms in these compounds and, thus, compounds 5 and $\mathbf{6}$ exist in the hydrazone form as well as theoretical calculations above suggest.

From comparison of NMR data (especially ${ }^{15} \mathrm{~N}$ chemical shifts and ${ }^{1} J$ $\left({ }^{15} \mathrm{~N},{ }^{1} \mathrm{H}\right)$ coupling constants, Tables 2 and 3$)$ for compounds 4-6 and those for compounds $\mathbf{1 - 3}$, it is clear that the tautomeric form in these compounds must be completely different. ${ }^{1} J\left({ }^{15} \mathrm{~N},{ }^{1} \mathrm{H}\right)$ coupling constants are the most illustrative: in the b-forms existing compounds 4-6 these constants are in the range of $95-100 \mathrm{~Hz}\left(-\mathrm{N}_{\alpha} \mathrm{H}-\right.$ form) while no ${ }^{1} J$ $\left({ }^{15} \mathrm{~N},{ }^{1} \mathrm{H}\right)$ coupling constants $\left(-\mathrm{N}_{\alpha}=\right.$ form $)$ were observed for compounds 1-3 existing thus in azo a-forms. Logically, the greatest changes are observable for $\mathrm{N}_{\alpha}$ that is directly involved in azo-hydrazo equilibrium.

The experimentally measured and theoretically predicted ${ }^{1} \mathrm{H}$ and ${ }^{13} \mathrm{C}$ chemical shifts for all studied compounds are compared in Tables 4 and 5 and S1-S4. Root mean square (RMS, in each of Tables 4 and 5, S1S4) and linearity (Tables S5 and S6) were used to estimate the reliability of the theoretical results.

The RMS values should show where the difference between measured data (the NH proton are excluded in 1-3) and predicted data of the corresponding (a or $\mathbf{b}$ ) tautomer are smaller and whether this can indicate which is the existing tautomer in solution. This definitely does not work in most of the cases of ${ }^{1} \mathrm{H}$ chemical shifts. Following this criterion for ${ }^{1} \mathrm{H}$ NMR, the tautomeric state is correctly predicted for $\mathbf{4 , 2}$ (by B3LYP only) and 6. For ${ }^{13} \mathrm{C}$ NMR correct prediction is available for all compounds except 3 , when B3LYP is used.

Following the linearity (Tables S5 and S6), the results for ${ }^{1} \mathrm{H}$ chemical shifts are mixed (Table S5). For instance there is better correlation for the a-form in 1-3, which is correct from the view point of experimental reality, but also better correlation for the same tautomer in 4-6 which is wrong. In the case of ${ }^{13} \mathrm{C}$ better correlation is obtained for the a-form of 1-3 and for the b-form of 4-6 (Table S6), which corresponds to the reality and to the RMS values. Consequently the predictive ability of the used level of theory is sufficient to reproduce the tautomeric state based on ${ }^{13} \mathrm{C}$ chemical shifts having in mind the systematic shift of the signals (intercepts in Table S6). It is difficult to make a statistically meaningful conclusion about the predictability of the ${ }^{15} \mathrm{~N}$ signals because the number of the experimental data is limited. It should be mentioned, however, that the B3LYP predictions in this case are nearer to the experiment as seen from Tables 4 and 5 .

\subsection{In the solid state}

According the crystallographic data of 1-6 the conclusions about their tautomerism in solution are valid in solid state as well. Compounds 1-3 are presented in their a-form, while 4-6 exists as ketolike b-tautomers. As will be shown below, the theoretically predicted geometries, given in Fig. 2, correspond very well to the crystal structures.

Compound 1 crystallizes in the monoclinic space group $P 2_{1} / \mathrm{c}$ with one molecule per asymmetric unit (Fig. 3). The phenyl ring $\mathrm{C} 11 \mathrm{~A} \rightarrow$ 

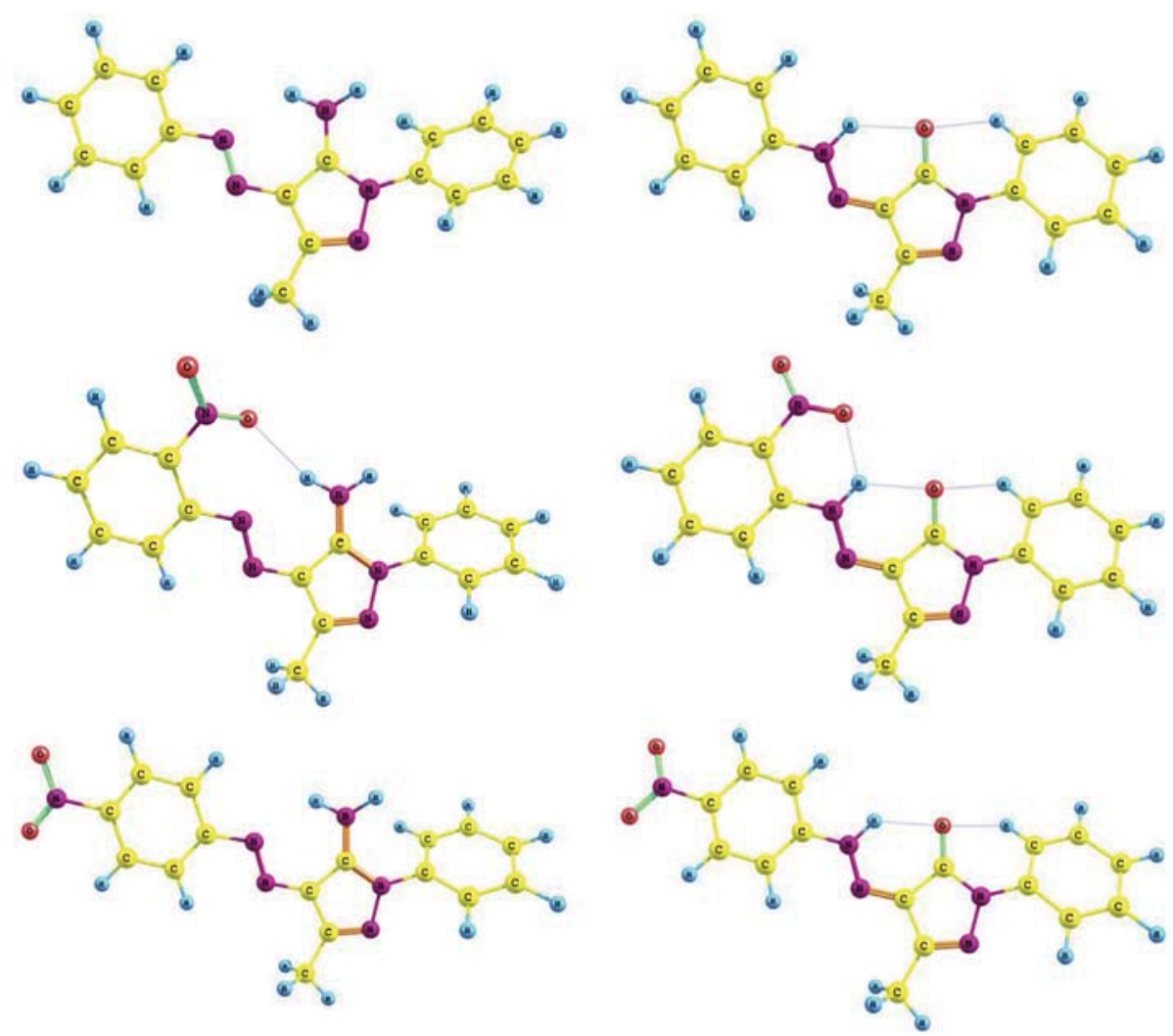

Fig. 2. The optimized structures (M06-2X/TZVP in acetonitrile) of the most stable a-tautomer of 1-3 (first column, from top to bottom) and b-tautomer of 4-6 (second column, from top to bottom).

Table 2

${ }^{1} \mathrm{H},{ }^{13} \mathrm{C}$ and ${ }^{15} \mathrm{~N}^{\mathrm{a}}$ chemical shifts (ppm) and ${ }^{1} J\left({ }^{15} \mathrm{~N},{ }^{1} \mathrm{H}\right){ }^{\mathrm{b}}$ coupling constants in compounds $\mathbf{1 - 3}$ in $\mathrm{CDCl}_{3}$.

\begin{tabular}{lllllll}
\hline $\mathrm{H} / \mathrm{C}$ & 1 & \multicolumn{5}{c}{3} \\
$\mathrm{nyyyyyy}$ & $\delta\left({ }^{1} \mathrm{H}\right)$ & $\delta\left({ }^{13} \mathrm{C}\right)$ & $\delta\left({ }^{1} \mathrm{H}\right)$ & $\delta\left({ }^{13} \mathrm{C}\right)$ & $\delta\left({ }^{1} \mathrm{H}\right)$ & $\delta\left({ }^{13} \mathrm{C}\right)$ \\
\hline 1 & - & $-197.0^{\mathrm{a}}$ & - & $-196.9^{\mathrm{a}}$ & - & $-197.4^{\mathrm{a}}$ \\
2 & - & $-102.9^{\mathrm{a}}$ & - & $-98.4^{\mathrm{a}}$ & - & $-98.6^{\mathrm{a}}$ \\
3 & - & 150.1 & - & $150.9^{2}$ & - & 150.6 \\
4 & - & 123.1 & - & 124.6 & - & 125.5 \\
5 & - & 137.7 & - & 136.9 & - & 138.6 \\
6 & - & 137.4 & - & 136.1 & - & 137.0 \\
7 & 7.54 & 123.4 & 7.52 & 123.4 & 7.52 & 123.5 \\
8 & 7.49 & 129.7 & 7.52 & 129.9 & 7.52 & 129.9 \\
9 & 7.37 & 127.8 & 7.41 & 128.2 & 7.40 & 128.1 \\
10 & 2.55 & 11.4 & 2.54 & 11.4 & 2.54 & 11.4 \\
$\mathrm{NH}_{2}$ & 6.23 & $-327.3^{\mathrm{a}}$ & 6.54 & $-323.2^{\mathrm{a}}$ & 6.66 & $-322.5^{\mathrm{a}}$ \\
$\left.{ }^{1} J{ }^{15} \mathrm{~N},{ }^{1} \mathrm{H}\right)$ & & $84.9^{\mathrm{b}}$ & & $90.3^{\mathrm{b}}$ & & $90.6^{\mathrm{b}}$ \\
$\mathrm{N}_{\alpha}$ & - & $54.7^{\mathrm{a}}$ & - & $34.8^{\mathrm{a}}$ & - & $25.3^{\mathrm{a}}$ \\
$\mathrm{N}_{\beta}$ & - & $98.1^{\mathrm{a}}$ & - & $104.1^{\mathrm{a}}$ & - & $98.5^{\mathrm{a}}$ \\
11 & - & 153.3 & - & 157.1 & - & 145.8 \\
12 & 7.72 & 121.1 & 7.79 & 121.3 & - & 145.6 \\
13 & 7.43 & 128.9 & 8.27 & 124.7 & 7.89 & 124.6 \\
14 & 7.31 & 128.3 & - & 146.4 & 7.36 & 127.4 \\
$\mathrm{NO}_{2}$ & - & - & - & $-12.8^{\mathrm{a}}$ & - & $-9.5^{\mathrm{a}}$ \\
& & & & & &
\end{tabular}

a $\delta\left({ }^{15} \mathrm{~N}\right)$

b ${ }^{1} J\left({ }^{15} \mathrm{~N},{ }^{1} \mathrm{H}\right)(\mathrm{Hz} \pm 0.3 \mathrm{~Hz})$.

C16A is split over two positions, one of which is dominant with a site of occupation factor (SOF) of $0.67(4)$, which will be used in the following discussion. The mean planes through the phenyl rings form an angle of $29.5^{\circ}$ (for $\mathrm{C} 11 \mathrm{~A} \rightarrow \mathrm{C} 16 \mathrm{~A}$, and $22.0^{\circ}$ for $\mathrm{C} 11 \rightarrow \mathrm{C} 16$ ), while these two rings form again an angle of 52.3 and $28.6^{\circ}$ (for $\mathrm{C} 11 \mathrm{~A} \rightarrow \mathrm{C} 16 \mathrm{~A}$, and $47.0^{\circ}$ for $\mathrm{C} 11 \rightarrow \mathrm{C} 16)$, respectively with the five-ring. The azo-bond N3-N4 is 1.287(7) $\AA$ long, while the hydrogen bonds between N4 and H5B is
Table 3

${ }^{1} \mathrm{H},{ }^{13} \mathrm{C}$ and ${ }^{15} \mathrm{~N}$ chemical shifts (ppm) and ${ }^{1} J\left({ }^{15} \mathrm{~N},{ }^{1} \mathrm{H}\right)$ coupling constants in compounds 4-6 in $\mathrm{CDCl}_{3}$.

\begin{tabular}{lllllll}
\hline $\mathrm{H} / \mathrm{C}$ & 4 & \multicolumn{5}{c}{5} \\
\cline { 2 - 7 } & $\delta\left({ }^{1} \mathrm{H}\right)$ & $\delta\left({ }^{13} \mathrm{C}\right)^{\mathrm{c}}$ & $\delta\left({ }^{1} \mathrm{H}\right)$ & $\delta\left({ }^{13} \mathrm{C}\right)^{\mathrm{c}}$ & $\delta\left({ }^{1} \mathrm{H}\right)$ & $\delta\left({ }^{13} \mathrm{C}\right)$ \\
\hline 1 & - & $-192.4^{\mathrm{a}}$ & - & $-191.9^{\mathrm{a}}$ & - & $-194.2^{\mathrm{a}}$ \\
2 & - & $-76.1^{\mathrm{a}}$ & - & $-67.4^{\mathrm{a}}$ & - & $-67.0^{\mathrm{a}}$ \\
3 & - & 148.3 & - & 148.6 & - & 148.5 \\
4 & - & 128.3 & - & 131.5 & - & 133.0 \\
5 & - & 157.6 & - & 157.2 & - & 156.4 \\
6 & - & 137.9 & - & 137.5 & - & 137.7 \\
7 & 7.97 & 118.3 & 7.91 & 118.4 & 8.01 & 118.5 \\
8 & 7.43 & 128.8 & 7.43 & 129.0 & 7.43 & 128.9 \\
9 & 7.22 & 124.9 & 7.22 & 125.5 & 7.22 & 125.4 \\
10 & 2.34 & 11.7 & 2.37 & 11.8 & 2.40 & 12.0 \\
$\mathrm{~N}_{\alpha}$ & 13.54 & $-205.6^{\mathrm{a}}$ & 13.55 & $-212.9^{\mathrm{a}}$ & 14.82 & $-219.1^{\mathrm{a}}$ \\
$\left.{ }^{1}{ }^{15} \mathrm{~N}_{\alpha},{ }^{1} \mathrm{H}\right)$ & - & $95.4^{\mathrm{b}}$ & - & $96.7^{\mathrm{b}}$ & - & $100.5^{\mathrm{b}}$ \\
$\mathrm{N}_{\beta}$ & - & $-18.9^{\mathrm{a}}$ & - & $-22.4^{\mathrm{a}}$ & - & $-28.7^{\mathrm{a}}$ \\
11 & - & 140.9 & - & 146.1 & - & 138.2 \\
13 & 7.40 & 129.5 & 7.47 & 125.7 & - & 135.2 \\
13 & 7.40 & 129.5 & 8.29 & 125.7 & 8.30 & 126.1 \\
14 & 7.22 & 125.6 & - & 144.4 & 7.26 & 123.9 \\
15 & 7.40 & 129.5 & 8.29 & 125.7 & 7.73 & 135.8 \\
16 & 7.40 & 129.5 & 7.47 & 125.7 & 8.19 & 116.8 \\
$\mathrm{NO}_{2}$ & - & - & - & n.o. & - & $-12.2^{\mathrm{a}}$ \\
\hline
\end{tabular}

$$
\begin{aligned}
& \text { a } \delta\left({ }^{15} \mathrm{~N}\right) . \\
& \text { b }{ }^{1} J\left({ }^{15} \mathrm{~N},{ }^{1} \mathrm{H}\right)(\mathrm{Hz} \pm 0.3 \mathrm{~Hz}) . \\
& \text { c } \text { Data are taken from Ref. [37]. }
\end{aligned}
$$

$2.51 \AA$ with an $\mathrm{H}$-bond angle of nearly $135^{\circ}$. The second H-atom H5A of N5 forms a longer H-bond towards N2 of a neighbor molecule with > $2.5 \AA$, governing the intermolecular interactions.

Compound 2, crystallizing in the monoclinic space group $\mathrm{C} 2 / \mathrm{c}$, features also a single molecule per asymmetric unit, whose azo bond N3-N4 is 1.29(10) A long (Fig. S3). The H-bond is characterized by a 


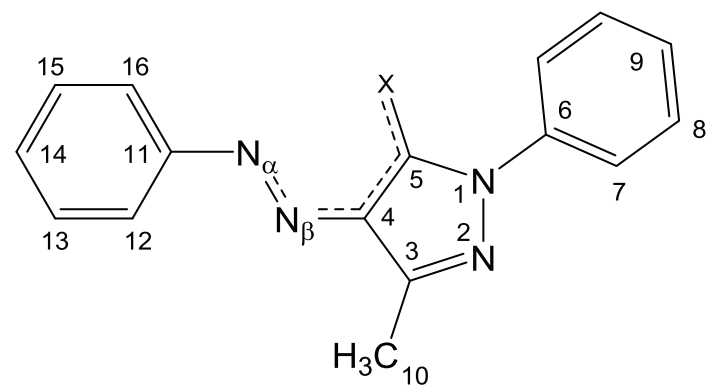

Scheme 2. Numbering of carbon and nitrogen atoms of interest.

distance of N4-H5A of $2.129 \AA$ and an N4-H5A-N5 angle of $120.4^{\circ}$. H5B forms a further H-bond to the nitro group of a neighbor molecule. Due to the presence of this nitro group, the aromatic systems form angles that are different than for $\mathbf{1}$ with $13.5^{\circ}$ between the 5-ring and the nitrophenyl moiety, and $32.1^{\circ}$ between the 5-ring and the phenyl entity. Furthermore, $\pi$-interactions can be found between the 5-ring of one molecule, and the nitrophenol-ring of a next neighbor molecule. The two 6-rings within the same molecule form an angle of ca. $19.3^{\circ}$.

For compound 3, which crystallizes in the trigonal space group $R-3$, the presence of the nitro group in para position with respect to the azo group seems to "planarize" the nitrophenyl ring with the 5-ring system, forming an angle of less than $4^{\circ}$ with each other (Fig. S4), while the phenyl group forms an angle of nearly $42^{\circ}$ with the 5-membered ring. The N3-N4 distance of the azo group is 1.287(3) A, with N4 forming an H-bond of $2.27 \AA$ with $\mathrm{H} 5 \mathrm{~B}$ at $120.4^{\circ}$. The second amine hydrogen atom $\mathrm{H} 5 \mathrm{~A}$ forms an intermolecular H-bond with $\mathrm{N} 2$ of a neighbor molecule at $2.34 \AA$. C11 of the nitrophenyl entity of one molecule features short contacts of ca. $3.3 \AA$ with N3 and lies thus "on top" of the azo group of antiparallel arranged next neighbor molecule.

Compound 4 crystallizes in the monoclinic space group $C 2 / \mathrm{c}$, has one molecule per asymmetric unit and is the first compound in this series with all aromatic rings quasi coplanar, with maximum deviations of $4^{\circ}$ between the rings (Fig. 4). The structure is now governed by an intramolecular $\mathrm{H}$-bond between $\mathrm{H} 4$ and $\mathrm{O} 1$ with $1.87 \AA$, forming an angle of $140.6^{\circ}$ between N4, $\mathrm{H} 4$ and $\mathrm{O} 1$. The bond N3-N4 is hence with $1.319(2) \AA$ longer than in the previous three structures, and also the distance C3-O1 is with 1.239(2) A slightly longer compared to average carbonyl $\mathrm{C}=\mathrm{O}$ bonds described in the CSD (mean $1.229 \AA$, std. dev: $0.024 \AA$, median $1.227 \AA$, mean dev.: $0.016 \AA$, statistics obtain with 88350 structures containing the motif $\mathrm{N}-(\mathrm{C}-) \mathrm{C}=\mathrm{O}$, resulting to 171294 distances [38]). This $\mathrm{C}=\mathrm{O}$ distance is in agreement of the distance already observed in the keto tautomer of 1-phenylazo-4-naphthol (1.242(4) A, CCDC-810700) [39]. The packing of the molecules is surprisingly not dominated by offset $\pi$-interactions, but rather by $\mathrm{C}-\mathrm{H}$ $\ldots \pi$ interactions of ca. $3.19 \AA$ between $\mathrm{H} 7$ and $\mathrm{H} 9$ of one molecule and C9 and C8 of a neighbor molecule, leading to a chevron-type arrangement of the molecules. Within a ribbon of parallel offset molecules, there are weak interactions (ca. $3.3 \AA$ ) between $\mathrm{C} 6-\mathrm{H} 6$ of one molecule and $\mathrm{H} 16-\mathrm{C} 16$ on the other.

The presence of the nitro group in compound $\mathbf{5}$, which crystallizes in the monoclinic space group $P 21 / \mathrm{c}$, leads to the formation of a bifurcated intramolecular H-bond between $\mathrm{H} 4$ and $\mathrm{O} 1$ (2.05 $\AA$ ) and $\mathrm{O} 2$ of the nitro group ( $1.99 \AA$ ) (Fig. S5). This leads to less coplanarity between the aromatic rings. The phenyl and the 5-ring form an angle of $9.8^{\circ}$, while the 5-ring and the nitrophenyl entity are inclined to each other by $8.9^{\circ}$. The mean planes through the two 6-rings form an angle of ca. $3.7^{\circ}$. This twist "out of mean plane" of the 5-ring with respect to the remaining molecule may be due to the presence of the tBu-group. Apparently as a result of this, the molecules pack in an antiparallel fashion, yielding in $\pi$-interactions between C14 and C15 of one molecule, and C4 and C6 of another molecule (and symmetry equivalents), with distances of 3.4-3.5 $\AA$. Short interactions are also found between $\mathrm{C} 2$ of one and $\mathrm{O} 2$ of another molecule (3.215 $\AA$ ), and $\mathrm{O} 1$ of one and C11 of a neighbor molecule (3.305 $\AA$ ). Further intermolecular interactions concern $\mathrm{O} 1$ and $\mathrm{O} 2$ of one molecule and $\mathrm{H} 6$ and $\mathrm{H} 7$, respectively, of an offset molecule, featuring distances in the order of $2.6-2.7 \AA$.

Like in compound 3 , the compound 6 , crystallizing in the space group $P 2_{1} / \mathrm{n}$, has the nitrophenyl moiety coplanar to the 5-ring, while the phenyl ring forms an angle of $12.7^{\circ}$ with respect to the central one (Fig. S6). The intramolecular H-bond of 2.06(2) ^ between $\mathrm{O} 1$ and $\mathrm{H} 4$ is characteristic of the structure. The molecules pack in an antiparallel, offset fashion and form pairwise short contacts between N4 of one and

Table 4

Predicted and experimental NMR parameters in ppm of selected atoms of $\mathbf{1}$ in chloroform

\begin{tabular}{|c|c|c|c|c|c|c|c|c|c|c|}
\hline \multirow{3}{*}{$\begin{array}{l}\mathrm{H} / \mathrm{C} \\
\mathrm{No}^{\mathrm{a}}\end{array}$} & \multicolumn{2}{|c|}{ experimental } & \multicolumn{4}{|c|}{ predicted (M062X/TZVP) } & \multicolumn{4}{|c|}{ predicted (B3LYP/6-311 + G(2d,p)) } \\
\hline & \multirow[b]{2}{*}{$\delta\left({ }^{1} \mathrm{H}\right)$} & \multirow[b]{2}{*}{$\delta\left({ }^{13} \mathrm{C}\right)$} & \multicolumn{2}{|l|}{$1 \mathrm{a}$} & \multicolumn{2}{|l|}{$1 \mathrm{~b}$} & \multicolumn{2}{|l|}{$1 \mathrm{a}$} & \multicolumn{2}{|l|}{$1 \mathrm{~b}$} \\
\hline & & & $\delta\left({ }^{1} \mathrm{H}\right)$ & $\delta\left({ }^{13} \mathrm{C}\right)$ & $\delta\left({ }^{1} \mathrm{H}\right)$ & $\delta\left({ }^{13} \mathrm{C}\right)$ & $\delta\left({ }^{1} \mathrm{H}\right)$ & $\delta\left({ }^{13} \mathrm{C}\right)$ & $\delta\left({ }^{1} \mathrm{H}\right)$ & $\delta\left({ }^{13} \mathrm{C}\right)$ \\
\hline 3 & - & 150.1 & - & 173.8 & & 171.8 & - & 163.0 & - & 159.5 \\
\hline 4 & - & 123.1 & - & 141.6 & - & 148.6 & - & 134.6 & - & 140.9 \\
\hline 5 & - & 137.7 & - & 153.7 & - & 170.7 & - & 146.7 & - & 161.4 \\
\hline 6 & - & 137.4 & - & 160.3 & - & 160.3 & - & 149.9 & - & 149.7 \\
\hline 7 & 7.54 & 123.4 & 8.58 & 146.9 & 8.39 & 144.6 & 8.18 & 134.8 & 7.99 & 132.7 \\
\hline 8 & 7.49 & 129.7 & 8.48 & 153.2 & 8.42 & 153.0 & 7.98 & 140.6 & 7.94 & 140.4 \\
\hline 9 & 7.37 & 127.8 & 8.27 & 149.7 & 8.15 & 147.5 & 7.77 & 136.8 & 7.65 & 134.9 \\
\hline 10 & 2.55 & 11.4 & 2.77 & 13.6 & 2.46 & 13.3 & 2.41 & 18.8 & 2.44 & 18.4 \\
\hline $\mathrm{N}_{\alpha}$ & - & $\begin{array}{l}54.7 \\
c\end{array}$ & - & $\begin{array}{l}93.1 \\
\mathrm{c}\end{array}$ & 14.25 & $\begin{array}{l}-261.3 \\
c\end{array}$ & - & $\begin{array}{l}51.6 \\
c\end{array}$ & 14.15 & -210.4 \\
\hline $\mathrm{N}_{\beta}$ & - & $\begin{array}{l}98.1 \\
c\end{array}$ & - & $\begin{array}{l}167.0 \\
c\end{array}$ & - & $\begin{array}{l}-33.1 \\
\mathrm{c}\end{array}$ & - & $\begin{array}{l}99.7 \\
c\end{array}$ & - & -36.1 \\
\hline 11 & - & 153.0 & - & 175.7 & - & 163.9 & - & 165.4 & - & 154.2 \\
\hline 12 & 7.72 & 121.1 & 8.80 & 131.2 & 8.71 & 131.4 & 8.46 & 122.0 & 8.35 & 121.9 \\
\hline 13 & 7.43 & 128.9 & 8.32 & 151.0 & 8.31 & 152.4 & 7.83 & 139.0 & 7.86 & 140.3 \\
\hline 14 & 7.31 & 128.3 & 8.23 & 151.3 & 7.92 & 145.3 & 7.72 & 138.2 & 7.51 & 133.8 \\
\hline NH2 & 6.23 & $\begin{array}{l}-327.3 \\
\mathrm{c}\end{array}$ & $7.90 / 4.76$ & $\begin{array}{l}-400.9 \\
c\end{array}$ & 14.25 & $\begin{array}{l}-255.8 \\
c\end{array}$ & $7.77 / 4.78$ & $\begin{array}{l}-338.8 \\
\mathrm{c}\end{array}$ & 14.22 & -217.6 \\
\hline$\underset{\mathrm{b}}{\mathrm{RMS}}$ & - & - & 0.90 & 20.23 & 0.78 & 20.81 & 0.50 & 10.32 & 0.40 & 11.51 \\
\hline
\end{tabular}

\footnotetext{
a See Scheme 2 for the atom numbering.

b Root mean square between experimental and predicted values for ${ }^{1} \mathrm{H}$ and ${ }^{13} \mathrm{C}$.

c $\delta\left({ }^{15} \mathrm{~N}\right)$.
} 
Table 5

Predicted and experimental NMR parameters in ppm of selected atoms of 4 in chloroform.

\begin{tabular}{|c|c|c|c|c|c|c|c|c|c|c|}
\hline \multirow{3}{*}{$\begin{array}{l}\mathrm{H} / \mathrm{C} \\
\mathrm{No}^{\mathrm{a}}\end{array}$} & \multicolumn{2}{|c|}{ experimental } & \multicolumn{4}{|c|}{ predicted (M062X/TZVP) } & \multicolumn{4}{|c|}{ predicted (B3LYP/6-311 + G(2d,p)) } \\
\hline & \multirow[b]{2}{*}{$\delta\left({ }^{1} \mathrm{H}\right)$} & \multirow[b]{2}{*}{$\delta\left({ }^{13} \mathrm{C}\right)$} & \multicolumn{2}{|l|}{$4 a$} & \multicolumn{2}{|l|}{$4 \mathrm{~b}$} & \multicolumn{2}{|l|}{$4 a$} & \multicolumn{2}{|l|}{$4 \mathrm{~b}$} \\
\hline & & & $\delta\left({ }^{1} \mathrm{H}\right)$ & $\delta\left({ }^{13} \mathrm{C}\right)$ & $\delta\left({ }^{1} \mathrm{H}\right)$ & $\delta\left({ }^{13} \mathrm{C}\right)$ & $\delta\left({ }^{1} \mathrm{H}\right)$ & $\delta\left({ }^{13} \mathrm{C}\right)$ & $\delta\left({ }^{1} \mathrm{H}\right)$ & $\delta\left({ }^{13} \mathrm{C}\right)$ \\
\hline 3 & - & 148.3 & - & 171.9 & - & 173.0 & - & 161.4 & - & 160.9 \\
\hline 4 & - & 128.3 & - & 140.9 & - & 145.8 & - & 133.6 & - & 137.8 \\
\hline 5 & - & 157.6 & - & 161.9 & - & 176.0 & - & 156.6 & - & 167.6 \\
\hline 6 & - & 137.9 & - & 159.3 & - & 160.2 & - & 149.4 & - & 149.8 \\
\hline 7 & 7.97 & 118.3 & 8.73 & 142.8 & 8.67 & 137.4 & 8.39 & 131.4 & 8.32 & 127.0 \\
\hline 8 & 7.43 & 128.8 & 8.49 & 151.8 & 8.32 & 151.2 & 7.92 & 139.4 & 7.84 & 138.8 \\
\hline 9 & 7.22 & 124.9 & 8.32 & 148.9 & 8.04 & 145.9 & 7.73 & 136.2 & 7.57 & 133.7 \\
\hline 10 & 2.34 & 11.7 & 2.61 & 13.8 & 2.54 & 14.0 & 2.79 & 19.0 & 2.51 & 19.0 \\
\hline $\mathrm{O} / \mathrm{N}_{\alpha}$ & 13.54 & -205.6 & 12.35 & $\begin{array}{l}50.8 \\
c\end{array}$ & 13.38 & $\begin{array}{l}-267.6 \\
\text { c }\end{array}$ & 11.85 & $\begin{array}{l}19.1 \\
c\end{array}$ & 13.45 & $\begin{array}{l}-216.1 \\
c\end{array}$ \\
\hline $\mathrm{N}_{\beta}$ & - & $\begin{array}{l}-18.9 \\
c\end{array}$ & - & $\begin{array}{l}181.5 \\
\mathrm{c}\end{array}$ & - & -22.4 & - & $\begin{array}{l}110.3 \\
c\end{array}$ & - & -27.5 \\
\hline 11 & - & 140.9 & - & 173.7 & - & 162.6 & - & 163.4 & - & 153.2 \\
\hline 12 & 7.40 & 129.5 & 8.77 & 132.0 & 8.73 & 132.3 & 8.18 & 122.8 & 8.38 & 122.7 \\
\hline 13 & 7.40 & 129.5 & 8.40 & 151.4 & 8.36 & 152.7 & 8.51 & 139.4 & 7.90 & 140.5 \\
\hline 14 & 7.22 & 125.6 & 8.21 & 153.1 & 8.05 & 147.4 & 7.88 & 139.9 & 7.63 & 135.7 \\
\hline 15 & 7.40 & 129.5 & 8.36 & 151.9 & 8.30 & 152.0 & 7.81 & 139.4 & 7.82 & 139.8 \\
\hline 16 & 7.40 & 129.5 & 8.79 & 151.6 & 7.87 & 136.5 & 7.94 & 139.4 & 7.51 & 126.7 \\
\hline $\mathrm{RMS}_{\mathrm{b}}$ & - & - & 1.11 & 21.10 & 0.72 & 19.14 & 0.80 & 11.53 & 0.45 & 9.78 \\
\hline
\end{tabular}

\footnotetext{
a See Scheme 2 for the atom numbering.

${ }^{\mathrm{b}}$ Root mean square between experimental and predicted values for ${ }^{1} \mathrm{H}$ and ${ }^{13} \mathrm{C}$. c $\delta\left({ }^{15} \mathrm{~N}\right)$.
}

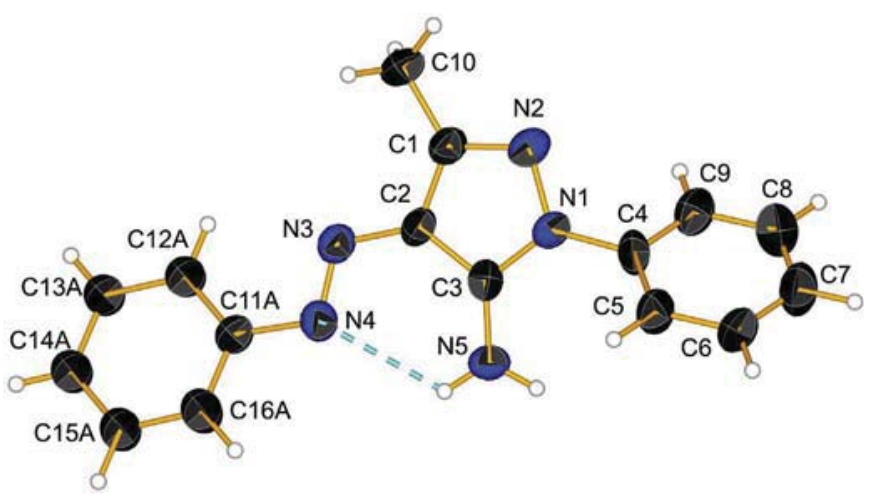

Fig. 3. Molecular view of $1,50 \%$ of probability, only one position of the ring $\mathrm{C} 11 \mathrm{~A} \rightarrow \mathrm{C} 16 \mathrm{~A}$ is represented (SOF 0.67), intramolecular hydrogen bond is drawn as dashed blue line. (For interpretation of the references to color in this figure legend, the reader is referred to the Web version of this article.)

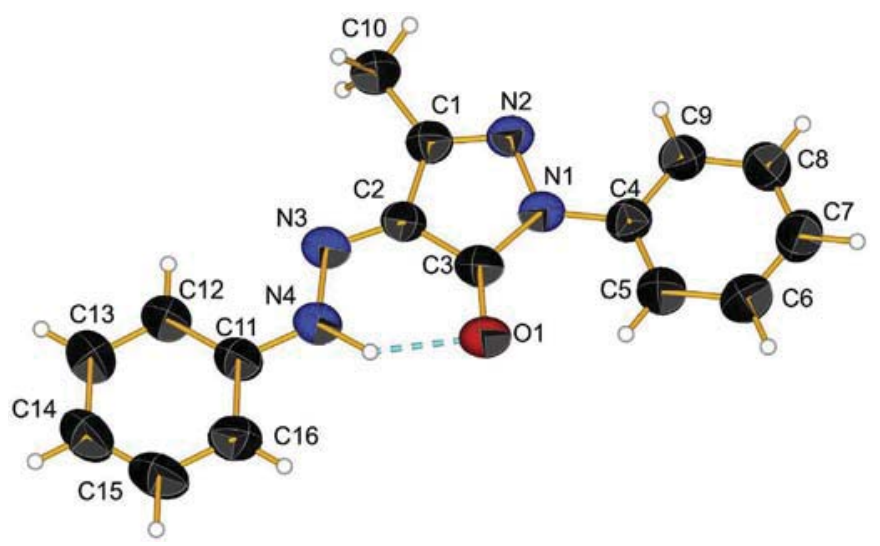

Fig. 4. Molecular view of 4, 50\% of probability, intramolecular hydrogen bond is drawn as dashed blue line. (For interpretation of the references to color in this figure legend, the reader is referred to the Web version of this article.)
N1 of a neighbor molecule (3.355 $\AA$ ), as well as O1 and C1 with $3.34 \AA$. There is also a short interaction between $\mathrm{H} 4$ of one and N2 of an antiparallel neighbor molecule $(3.28 \AA)$. The molecules further pack also into chains with interactions between the $\mathrm{H}$-atoms $\mathrm{H7}$ and $\mathrm{H} 8$ of the phenyl ring, and $\mathrm{O} 3$ and $\mathrm{O} 2$, respectively, of the next neighbor nitro group $(2.6-2.75 \AA)$.

The most important bond lengths and angles of all six structures are compared in Table 6. As seen the bond distances in the fragment N4-X (Scheme S1) very nicely confirm the tautomeric state according to published results for other tautomeric azo compounds [39].

In conclusion, the compounds 1-3 correspond to the a-form (enoltype), and do not present coplanarity of the aromatic rings. On the other hand, compounds 4-6 are in the keto-form, in which the aromatic rings are mostly coplanar.

\section{Conclusions}

Two classes of organic azo dyes were prepared by diazonium salts coupling reactions with two formally very similar passive component differing only in substitution in position 5 of pyrazole ring: $\mathrm{NH}_{2}$ or $\mathrm{OH}$ (in equilibrium with appropriate tautomeric form). The corresponding reaction products 1-3 and 4-6 were investigated in relation to their tautomerism in solution and in solid state. According to the theoretical calculations and NMR studies compounds 1-3 are presented in their azo enol-like tautomeric form, while compounds 4-6 exist as hydrazone tautomers. The nitro substitution in the phenyl ring does not influence

Table 6

Direct comparison of important bond lengths $(\AA)$ and angles $\left(^{\circ}\right)$ of compounds 1-6 ( $\mathrm{X}$ is $\mathrm{N}$ for $1-3$ or O for $4-6$ ).

\begin{tabular}{lllllll}
\hline Bond & 1 & 2 & 3 & 4 & 5 & 6 \\
\hline $\mathrm{N} 4-\mathrm{N} 3$ & $1.287(8)$ & $1.29(1)$ & $1.287(2)$ & $1.319(2)$ & $1.331(3)$ & $1.320(4)$ \\
$\mathrm{N} 3-\mathrm{C} 2$ & $1.390(8)$ & $1.36(1)$ & $1.368(3)$ & $1.324(2)$ & $1.306(3)$ & $1.305(3)$ \\
$\mathrm{C} 2-\mathrm{C} 3$ & $1.394(9)$ & $1.41(1)$ & $1.414(4)$ & $1.454(3)$ & $1.470(4)$ & $1.457(3)$ \\
$\mathrm{C} 3-\mathrm{X}$ & $1.345(9)$ & $1.33(1)$ & $1.336(3)$ & $1.239(2)$ & $1.232(3)$ & $1.227(3)$ \\
$\mathrm{N} 4 \cdots \mathrm{X}$ & $2.869(8)$ & $/$ & $2.806(3)$ & $2.712(2)$ & $2.773(3)$ & $2.783(3)$ \\
$\alpha\left(\mathrm{N} 4-\mathrm{H}^{\cdots} \mathrm{X}\right)$ & $118.4^{\circ}$ & $/$ & $120.4^{\circ}$ & $141(1)^{\circ}$ & $143(1)^{\circ}$ & $137(2)^{\circ}$ \\
\hline
\end{tabular}


substantially actually tautomeric state. The crystallographic data support the conclusions from solution and show that the stabilization of the tautomers is not a result of intermolecular interactions. As a result the first set of compounds can be used as NMR references for azo tautomer, while the others represent pure hydrazo form.

\section{Acknowledgements}

The generous financial support by the Swiss National Science Foundation, Institutional Partnership project IZ74Z0_160515 (SupraMedChem@Balkans.Net SCOPES Institutional Partnership) is gratefully acknowledged. We acknowledge that the theoretical results of this research have been achieved using the DECI resource Cartesius based in the Netherlands at SURFsara with support from the PRACE aisbl (project pr2i0035).

\section{Appendix A. Supplementary data}

Supplementary data to this article can be found online at https:// doi.org/10.1016/j.dyepig.2019.02.015.

\section{References}

[1] Zollinger H. Color chemistry: syntheses, properties, and applications of organic dyes and pigments. 3rd Zürich: Weinheim: Verlag Helvetica Chimica Acta; Wiley-VCH; 2003.

[2] Kelemen J. Azo-hydrazone tautomerism in azo dyes. I. A comparative study of 1phenylazo-2-naphthol and 1-phenylazo-2-naphthylamine derivatives by electronic spectroscopy «. Dyes Pigments 1981;2:73-91. https://doi.org/10.1016/01437208(81)80009-5.

[3] Kelemen J, Moss S, Sauter H, Winkler T. Azo-hydrazone tautomerism in azo dyes. II. Raman, NMR and mass spectrometric investigations of 1-phenylazo-2-naphthylamine and 1-phenylazo-2-naphthol derivatives. Dyes Pigments 1982;3:27-47. https://doi.org/10.1016/0143-7208(82)80011-9.

[4] Kelemen J. Azo-hydrazone tautomerism in azo dyes. III. The tautomeric structure of 1-(4'-nitrophenylazo)-2-naphthylamine from crystal structure determination. Dyes Pigments 1982;3:249-71. https://doi.org/10.1016/0143-7208(82)80001-6.

[5] Kelemen J, Moss S, Glitsch S. Azo-hydrazone tautomerism in azo dyes. IV. Colour and tautomeric structure of adsorbed 1-phenylazo-2-naphthylamine and 1-phenylazo-2-naphthol dyes. Dyes Pigments 1984;5:83-108. https://doi.org/10.1016/ 0143-7208(84)80007-8.

[6] Antonov L, editor. Tautomerism: methods and theories. Weinheim: Wiley-VCH; 2014.

[7] Gordon PF, Gregory P. Azo dyes. Org. Chem. Colour. Berlin: Springer-Verlag; 1987. p. 95-162.

[8] Antonov L, Hansen PE, Zwan G van der. Comment on "Spectroscopic studies of keto-enol tautomeric equilibrium of azo dyes". Rauf MA, Hisaindee S, Saleh N, editors. RSC adv, vol. 5. 2015. p. 18097. https://doi.org/10.1039/C5RA10553F. RSC Adv 2015;5:67165-67167.

[9] Elguero J. Tautomerism: a historical perspective. In: Antonov L, editor. Tautomerism concepts appl. Sci. Technol. Weinheim, Germany: Wiley-VCH; 2016. p. 1-10. https://doi.org/10.1002/9783527695713.ch1.

[10] Nedeltcheva D, Antonov L, Lycka A, Damyanova B, Popov S. Chemometric models for quantitative analysis of tautomeric schiff bases and azo dyes. Curr Org Chem 2009;13:217-40. https://doi.org/10.2174/138527209787314832.

[11] Antonov L, Nedeltcheva D. Resolution of overlapping UV-Vis absorption bands and quantitative analysis. Chem Soc Rev 2000;29:217-27. https://doi.org/10.1039/ a900007k.

[12] Antonov L. Absorption UV-vis spectroscopy and chemometrics: from qualitative conclusions to quantitative analysis. In: Antonov L, editor. Tautomerism methods theor. Weinheim, Germany: Wiley-VCH; 2013. p. 25-47.

[13] Kleinpeter E. NMR spectroscopic study of tautomerism in solution and in the solid state. In: Antonov L, editor. Tautomerism methods theor Weinheim, Germany: Wiley-VCH Verlag GmbH \& Co. KGaA; 2013. p. 103-43. https://doi.org/10.1002/ 9783527658824.ch5.

[14] Berger S, Braun S. 200 and more NMR experiments: a practical course. 3rd rev
Weinheim: Wiley-VCH; 2004. expanded ed.

[15] Claridge TDW. High-resolution NMR techniques in organic chemistry. third ed. Amsterdam Boston Heidelberg London New York Oxford Paris: Elsevier; 2016.

[16] Marek R, Lycka A, Kolehmainen E, Sievanen E, Tousek J. 15N NMR spectroscopy in structural analysis: an update (2001 - 2005). Curr Org Chem 2007;11:1154-205. https://doi.org/10.2174/138527207781662519.

[17] Dolomanov OV, Bourhis LJ, Gildea RJ, Howard JAK, Puschmann H. OLEX2 : a complete structure solution, refinement and analysis program. J Appl Crystallogr 2009;42:339-41. https://doi.org/10.1107/S0021889808042726.

[18] Sheldrick GM. Crystal structure refinement with SHELXL. Acta Crystallogr Sect C Struct Chem 2015;71:3-8. https://doi.org/10.1107/S2053229614024218.

[19] Sheldrick GM. SHELXT - integrated space-group and crystal-structure determination. Acta Crystallogr Sect Found Adv 2015;71:3-8. https://doi.org/10.1107/ S2053273314026370.

[20] Frisch MJ, Trucks GW, Schlegel HB, Scuseria GE, Robb MA, Cheeseman JR, et al. Gaussian 09 revision D.01. Wallingford, CT, USA: Gaussian, Inc.; 2013.

[21] Zhao Y, Truhlar DG. The M06 suite of density functionals for main group thermochemistry, thermochemical kinetics, noncovalent interactions, excited states, and transition elements: two new functionals and systematic testing of four M06-class functionals and 12 other functionals. Theor Chem Acc 2008;120:215-41. https:// doi.org/10.1007/s00214-007-0310-x.

[22] Zhao Y, Truhlar DG. Density functionals with broad applicability in chemistry. Acc Chem Res 2008;41:157-67. https://doi.org/10.1021/ar700111a.

[23] Weigend F, Ahlrichs R. Balanced basis sets of split valence, triple zeta valence and quadruple zeta valence quality for $\mathrm{H}$ to $\mathrm{Rn}$ : design and assessment of accuracy. Phys Chem Chem Phys 2005;7:3297. https://doi.org/10.1039/b508541a.

[24] Kawauchi S, Antonov L. Description of the tautomerism in some azonaphthols. J Phys Org Chem 2013;26:643-52. https://doi.org/10.1002/poc.3143.

[25] Hristova S, Deneva V, Pittelkow M, Crochet A, Kamounah FS, Fromm KM, et al. A concept for stimulated proton transfer in 1-(phenyldiazenyl)naphthalen-2-ols. Dyes Pigments 2018;156:91-9. https://doi.org/10.1016/j.dyepig.2018.03.070.

[26] Manolova Y, Marciniak H, Tschierlei S, Fennel F, Kamounah FS, Lochbrunner S, et al. Solvent control of intramolecular proton transfer: is 4-hydroxy-3-(piperidin-1ylmethyl)-1-naphthaldehyde a proton crane? Phys Chem Chem Phys 2017;19:7316-25. https://doi.org/10.1039/C7CP00220C.

[27] Tomasi J, Mennucci B, Cammi R. Quantum mechanical Continuum solvation models. Chem Rev 2005;105:2999-3094. https://doi.org/10.1021/cr9904009.

[28] Jacquemin D, Mennucci B, Adamo C. Excited-state calculations with TD-DFT: from benchmarks to simulations in complex environments. Phys Chem Chem Phys 2011;13:16987. https://doi.org/10.1039/c1cp22144b.

[29] Laurent AD, Adamo C, Jacquemin D. Dye chemistry with time-dependent density functional theory. Phys Chem Chem Phys 2014;16:14334. https://doi.org/10. 1039/c3cp55336a.

[30] Savarese M, Brémond É, Antonov L, Ciofini I, Adamo C. Computational insights into excited-state proton-transfer reactions in azo and azomethine dyes. ChemPhysChem 2015;16:3966-73. https://doi.org/10.1002/cphc.201500589.

[31] Adamo C, Jacquemin D. The calculations of excited-state properties with time-dependent density functional theory. Chem Soc Rev 2013;42:845-56. https://doi.org/ $10.1039 / \mathrm{c} 2 \mathrm{cs} 35394 \mathrm{f}$

[32] Antonov L, Kawauchi S, Okuno Y. Prediction of the color of dyes by using timedependent density functional theory. Bulg Chem Commun 2014;46:228-37.

[33] Wolinski K, Hinton JF, Pulay P. Efficient implementation of the gauge-independent atomic orbital method for NMR chemical shift calculations. J Am Chem Soc 1990;112:8251-60. https://doi.org/10.1021/ja00179a005.

[34] Cheeseman JR, Trucks GW, Keith TA, Frisch MJ. A comparison of models for calculating nuclear magnetic resonance shielding tensors. J Chem Phys 1996;104:5497-509. https://doi.org/10.1063/1.471789.

[35] Hristova S, Angelova S, Hansen PE, Antonov L. 4-Carboxyl-2,6-dinitrophenylazohydroxynaphthalenes tautomerism NMR re-explained and other methods verified. Dyes Pigments 2017;142:226-9. https://doi.org/10.1016/j. dyepig.2017.03.037.

[36] Bekárek Y, Rothschein K, Vetešník P, Večeřa M. Estimation of azo - hydrazo tautomeric equilibrium in ortho-hydroxy-azocompounds by N.M.R. Tetrahedron Lett 1968;9:3711-3. https://doi.org/10.1016/S0040-4039(00)75523-7.

[37] Lyčka A, Liptaj T, Jirman J. 13C and 15N NMR spectra of 3-methyl-1-phenylpyrazole-4,5-dione 4-(4'-substituted phenyl)hydrazones. Collect Czechoslov Chem Commun 1987;52:727-35. https://doi.org/10.1135/cccc19870727.

[38] Cambridge structural database 5.39 update Feb. 2018. Cambridge Crystallographic Data Centre; 2018

[39] Antonov L, Kurteva V, Crochet A, Mirolo L, Fromm KM, Angelova S. Tautomerism in 1-phenylazo-4-naphthols: experimental results vs quantum-chemical predictions. Dyes Pigments 2012;92:714-23. https://doi.org/10.1016/j.dyepig.2011.06.026. 